\title{
Stability-indicating HPLC-DAD method for the determination of empagliflozin
}

\author{
Shilpi Pathak ${ }^{*}$ (D) and Pradeep Mishra
}

\begin{abstract}
Background: A stability-indicating RP-HPLC method was developed and validated for the estimation of empagliflozin drug and its tablet dosage form using a DAD detector. The mobile phase consisted of methanol/ acetonitrile/0.1\%OPA (75:20:5). The peak was observed at 2.54 min using $222.0 \mathrm{~nm}$ absorption maxima.
\end{abstract}

Results: Calibration curve plot was found within the range of $10-50 \mu \mathrm{g} / \mathrm{mL}$. The coefficient of determination $\left(R^{2}\right)$ was found to be 0.9990 . Forced degradation studies were performed for the empagliflozin in various conditions, and the results were calculated as \%RSD values and were found to be within the limits.

Conclusion: The method was validated as per ICH guidelines with respect to all validation parameters.

Keywords: Empagliflozin, RP-HPLC, Stress study, Validation, DAD detector

\section{Background}

Empagliflozin a new oral antidiabetic drug is a selective sodium-glucose transport protein 2 (SGLT2) inhibitor. The drug is given as a film-coated pill containing either 10 or $25 \mathrm{mg}$ of empagliflozin as an active pharmaceutical ingredient. The drug was permitted by The United States Food and Drug Administration (USFDA) in 2014 [1].

The chemical name of empagliflozin is (1S)-1,5-anhydro-1-(4-chloro-3-\{4-[(3S)-tetrahydrofuran-3-yloxy] benzyl\}phenyl)-D-glucitol, also known as D-Glucitol,1,5anhydro-1-C-[4-chloro-3- [[4-[[(3S)-tetrahydro-3-furanyl]oxy]phenyl]methyl]phenyl]-(1S), and structure is shown in Fig. 1.

It is a white to yellowish non-hygroscopic crystalline solid, very slightly soluble in water, slightly soluble in acetonitrile and ethanol, sparingly soluble in methanol, and practically insoluble in toluene [2]. Being sodium-glucose co-transporter 2(SGLT2) inhibitor in nature, it is probably the latest class of medicine in the treatment of T2DM. SGLT2 being glucose-lowering agents shows an insulin-independent mechanism which also proves their use in other treatments along with combination of other anti-diabetic agents for the treatment of T2DM. Additionally, it contributes to reduced hyperglycemia, assists weight loss, and reduces blood pressure $[3,4]$. The physico-chemical parameters [5] are shown in Table 1.

Very few studies were done on the empagliflozin as a single drug assay (HPLC) [6-8]. Jaiswal et al. identified and quantified empagliflozin in the presence of four related impurities using HPLC [9]. Ayoub et al. gave pharmaceutical evaluation using LC-MS technique [10]. Various studies performed the HPLC method on different combinations of drugs with empagliflozin [11-16]. One HPTLC method was reported in combination of drugs [17]. However, the reported methods are not suitable for quick analysis as the retention time is quite high and the methods are incompatible for coupling with a mass detector. Moreover, no stability-indicating assay is reported to date. Thus, in the proposed work, stress studies and tablet analysis were performed using HPLC equipped with a DAD detector. Moreover, the proposed method is economic as less solvent will be consumed due to short running time.

*Correspondence: shilpi.pathak@gla.ac.in

Institute of Pharmaceutical Research, GLA University, Mathura, UP 281406,

India 
<smiles>OCC1OC(c2ccc(Cl)c(Cc3ccc(OC4CCOC4)cc3)c2)[C@H](O)[C@@H](O)[C@@H]1O</smiles>

Fig. 1 Structure of empagliflozin

Table 1 Critical physico-chemical parameters

\begin{tabular}{ll}
\hline Parameter & Description \\
\hline CAS Number & $864077-44-0$ \\
Molecular formula & $\mathrm{C}_{23} \mathrm{H}_{27} \mathrm{ClO}_{7}$ \\
Molecular weight & 450.9 \\
Appearance & Crystalline Solid \\
Melting point & $151.0-153.0^{\circ} \mathrm{C}$ \\
Solubility & Methanol, Ethanol, \\
& Dimethyl sul- \\
Drug type & foxide \\
\hline
\end{tabular}

\section{Methods}

\section{Chemicals}

Empagliflozin (99.91\%) was received as a gift sample from Manus Aktteva Biopharma LLP, Ahmedabad, India. To assess the purity of the drug, melting point was determined which was found as per the literature. Thus, the drug was used without further purification. Methanol, acetonitrile and water of HPLC grade were obtained from Spectrochem Pvt. Ltd., Mumbai. Ortho-phosphoric acid was obtained from E. Merck India Ltd. Mumbai. Film-coated tablet formulations were purchased by a local pharmacy. All analytical grade chemicals were used throughout the analysis.

\section{Equipment}

Agilent HPLC 1260 Infinity II Quaternary Pump VL system with a DAD Detector was utilized. Separation was carried out on a particle size Poroshell 120 EC-C18, $4.6 \times 100 \mathrm{~mm}, 4 \mu \mathrm{m}$ column (at ambient temperature), and isocratic runs under RP-HPLC condition. The instrument was controlled by a PC with properly connected chromatographic software.

\section{Chromatographic conditions}

Using a gradient mode, fifty trials of HPLC methods using acetonitrile, water, methanol, and various buffers in different ratios were explored to optimize the separation of empagliflozin. The optimized mobile phase was

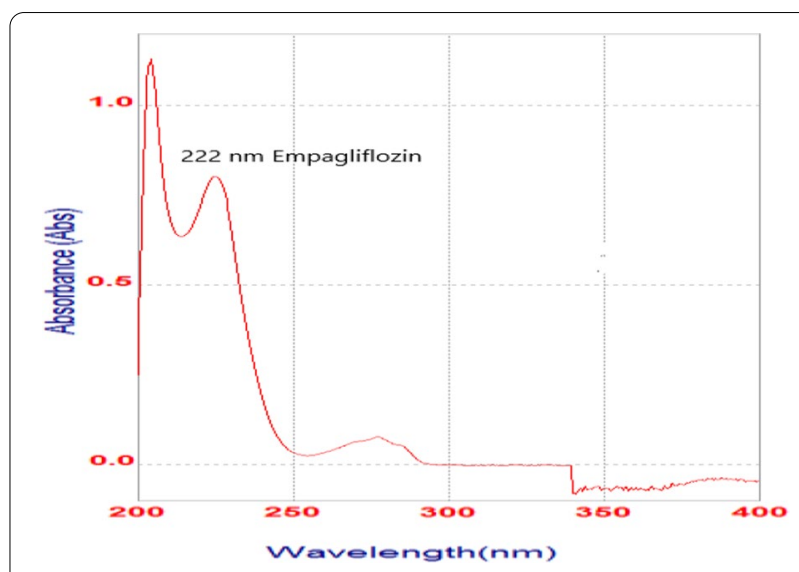

Fig. 2 UV spectrum of empagliflozin

Table 2 Optimized chromatographic conditions of empagliflozin

\begin{tabular}{ll}
\hline Parameters & Conditions \\
\hline Stationary phase & $\mathrm{C}_{18}(4.6 \times 100 \mathrm{~mm}, 4 \mu \mathrm{m})$ \\
Mobile phase & Methanol/ \\
& Acetonitrile/0.1\%OPA \\
& $(75: 20: 5)$ \\
Flow rate $(\mathrm{mL} / \mathrm{min})$ & 1.0 \\
Run time $(\mathrm{min})$ & 10 \\
Detection wavelength $(\mathrm{nm})$ & 222.0 \\
Injection volume $(\mu \mathrm{L})$ & 20 \\
Retention time $(\mathrm{min})$ & 2.54 \\
\hline
\end{tabular}

prepared by mixing methanol/acetonitrile/ $0.1 \%$ OPA (75:20:5) that was filtered and degassed properly before use. The UV detection was carried at $222.0 \mathrm{~nm}$ (Fig. 2).

The trials were introduced via a rheodyne injector. The entire determination was performed for $10 \mathrm{~min}$. All the sample and mobile phase preparation were done regularly. The separation conditions are shown in Table 2.

\section{Method validation}

Validation parameters consist of linearity, accuracy, precision, robustness, ruggedness, detection limit, quantification limit and stability studies. Relative standard deviation less than $2 \%$ was considered and acceptable [18].

\section{Linearity}

Accurately weighed $100 \mathrm{mg}$ of drug is dissolved in 100$\mathrm{mL}$ volumetric flask and then suitably diluted to give $1000 \mu \mathrm{g} / \mathrm{mL}$ stock solution. Aliquots of $0.1,0.2,0.3,0.4$ and $0.5 \mathrm{~mL}$ from stock solution were pipetted out in 10 - $\mathrm{mL}$ volumetric flask and volume was made up to the mark with methanol to get the concentrations of 10,20 , 
$30,40,50 \mu \mathrm{g} / \mathrm{mL}$, and their chromatogram was recorded at the optimized condition. The concluding concentration of the drug was in the series of $10-50 \mu \mathrm{g} / \mathrm{mL}$. Peak area was recorded for the calibration curve construction. The value of coefficient of determination $\left(R^{2}\right)$ evaluated the calibration curve.

\section{Accuracy}

Standard addition method was used for the evaluation of accuracy, i.e., quantification of the recovery of analyte. To known drug solution, a certain amount of standard drug was added. The different $80 \%, 100 \%$ and $120 \%$ levels of drug were compared with standard values of drug obtained. Replicate analysis was done on this parameter.

\section{Precision}

The precision of the method was determined by obtained peak area of different replication of a fixed amount of the drug $(10 \mu \mathrm{g} / \mathrm{mL})$. It is resolute in terms of inter- and intra-day precision. Variations of inter-day and intra-day in the peak areas of drug concentration on three different days are calculated in terms of \%RSD.

\section{Robustness}

Robustness of method was determined by making changes in flow rate, temperature, and wavelength. The percentage relative standard deviation noted for empagliflozin should be less than 2 according to ICH guidelines.

\section{Repeatability}

It was determined by multiple homogenous analyzing sample solution $10 \mu \mathrm{g} / \mathrm{mL}$ of empagliflozin into system and measured the peak area. It was repeated six times.

\section{Detection limit and quantitation limit}

The limit of detection (LOD) and the limit of quantitation (LOQ) were calculated by following formulas

$$
\begin{aligned}
& \mathrm{LOD}=3.3 \mathrm{SD} / \text { Slope } \\
& \mathrm{LOQ}=10 \mathrm{SD} / \text { Slope }
\end{aligned}
$$

$\mathrm{SD}$ is the standard deviation of the $y$-intercept of the regression line.

\section{Analysis of marketed formulations}

Two tablets from peeled off ones were powdered. The powder representing $10 \mathrm{mg}$ of empagliflozin was taken in a clean beaker. Approximately, $50 \mathrm{~mL}$ methanol was added to solubilize the analyte. Then, the solution was filtered using a Whatman filter paper in to a $100-\mathrm{mL}$ volumetric flask to remove the excipients. The whole material from the beaker was transferred quantitatively to volumetric flask then made up the volume. The final solution of $100 \mu \mathrm{g} / \mathrm{mL}$ was made. From this stock solution, $1 \mathrm{~mL}$ solution was pipetted out and added to a $10-\mathrm{mL}$ volumetric flask and volume made up with methanol. Solution so obtained was filtered through with $0.2-\mu \mathrm{m}$ nylon membrane filter paper to get the final solution ready for HPLC instrument. Using a provided rheodyne injector, $20 \mu \mathrm{L}$ of the sample was fed to the column. The instrument was allowed to run with already established solvent system and method followed. The value of the drug sample under the peak was calculated using the graph shown in Fig. 3.

\section{Forced degradation studies}

In these studies, we can interpret the acid, base, oxidation, thermal, photolytic degradation in the sample.

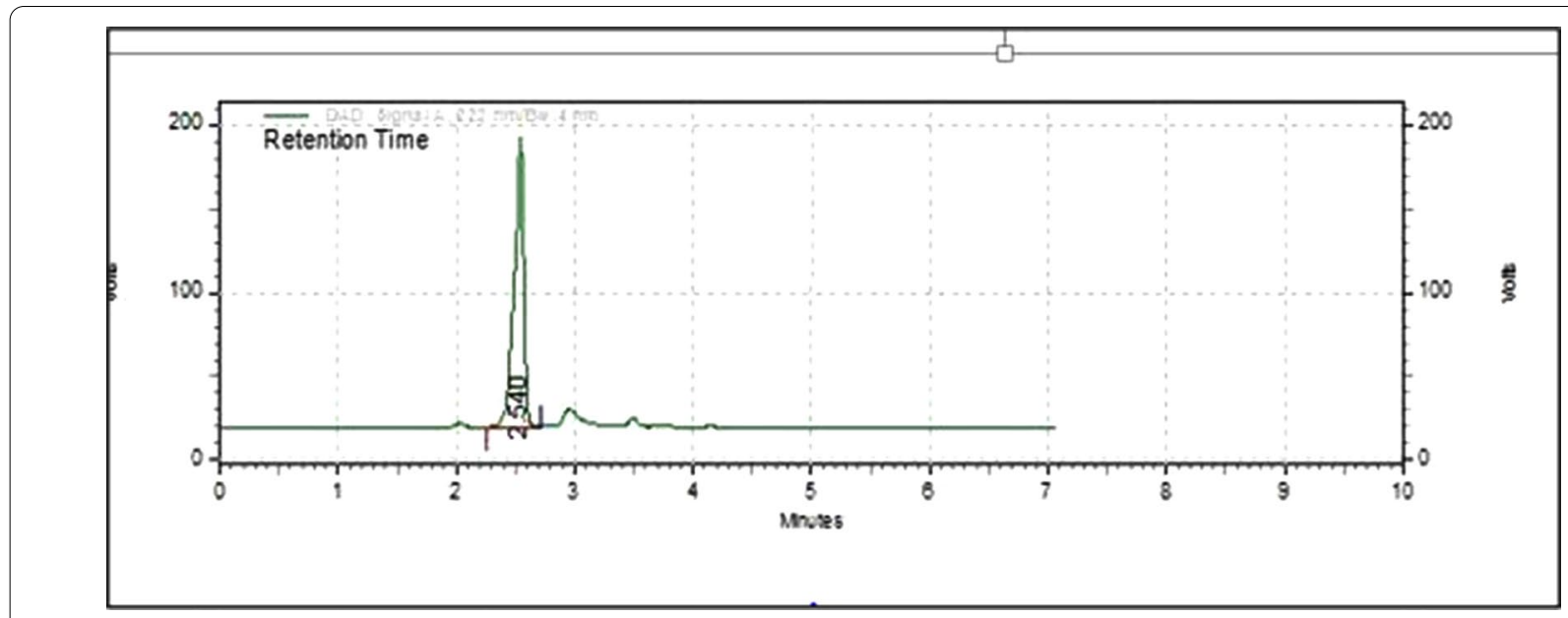

Fig. $3 \mathrm{HPLC}$ chromatogram of empagliflozin at $222.0 \mathrm{~nm}$ 
Separation of degradation product from the pure active ingredient is studied by the obtained peak under stressed condition [9]. In acid degradation when the drug interacts with acid it produces primary degradation in the desirable range. For acid analysis $\mathrm{HCl}$ or $\mathrm{H}_{2} \mathrm{SO}_{4}(0.1-1 \mathrm{M})$ is widely used. In basic degradation when the drug interacts with base it produces primary degradation in the desirable range. For base analysis, $\mathrm{NaOH}$ or $\mathrm{KOH}(0.1-1 \mathrm{M})$ is widely used. In oxidative degradation hydrogen peroxide is widely used for oxidation degradation. Drug structure will allow selecting concentration and condition of oxidizing agent. In light stress, the empagliflozin was open to direct daylight for calculating degradation. The drug was used at different intervals and injected into a system for determining degradation of the drug. In thermal degradation according to $\mathrm{ICH}$ Q1A accelerated testing condition, thermal degradation should be carried out in dry heat or wet heat. Study may be conducted at high temperatures for a short period [19].

\section{Results}

Various chromatographic methods were tried to optimize the separation of empagliflozin. Mobile phase, retention time, flow rate and other optimized condition are shown in Table 2.The linear relationship was determined by plotting the calibration curve. The equation of regression line showed that $R^{2}, \mathrm{~m}$ and $\mathrm{C}$ for empagliflozin were $0.9990,8997.2$, and 118,538 , respectively. The RT for empagliflozin was $2.54 \mathrm{~min}$. Separation of empagliflozin at $222.0 \mathrm{~nm}$ and calibration curve are shown in Figs. 3 and 4 , respectively.

In the optimized method, the range of linearity was observed in $10-50 \mu \mathrm{g} / \mathrm{mL}$. The linearity was determined by the least square regression method, and the value of
$R^{2}$ was 0.9990 as shown in Fig. 2. The recovery result determines the accuracy of the method and is shown in Table 3.

Precision results of the RP-HPLC method for empagliflozin are shown in Table 4.

Robustness is determined by performing the analysis at slightly different flow rate, mobile phase, temperature and wavelength from optimized chromatographic condition. The results are given in Table 5.

The limit of detection and limit of quantitation of empagliflozin were determined to be 0.05 and $0.1 \mu \mathrm{g} / \mathrm{mL}$, respectively.

\section{Analysis of marketed formulations}

The developed method was validated and effectively applied to determine empagliflozin in different formulations. Three replicates determination was made for each observation as shown in Table 6.

Forced degradation studies of empagliflozin were done in different conditions as per the ICH guidelines. Acid degradation of empagliflozin was performed in $0.1 \mathrm{~N}$ $\mathrm{HCl}$ and weighed $10 \mathrm{mg}$ of drug accurately and transferred to a $100-\mathrm{mL}$ clean volumetric flask and dissolved in 5 to $10 \mathrm{~mL}$ methanol. The volume was made up with $0.1 \mathrm{~N} \mathrm{HCl}$ solution and kept at room temperature. One

Table 3 Accuracy of empagliflozin

\begin{tabular}{|c|c|c|c|c|}
\hline Drug \% & $\begin{array}{l}\text { Initial } \\
\text { amount } \\
(\mu \mathrm{g} / \mathrm{mL})\end{array}$ & $\begin{array}{l}\text { Amount added } \\
(\mu \mathrm{g} / \mathrm{mL})\end{array}$ & \% Recovery & \%RSD \\
\hline 80 & 10 & 8 & 99.29 & 0.155 \\
\hline 100 & 10 & 10 & 99.14 & 0.120 \\
\hline 120 & 10 & 12 & 99.28 & 0.472 \\
\hline
\end{tabular}

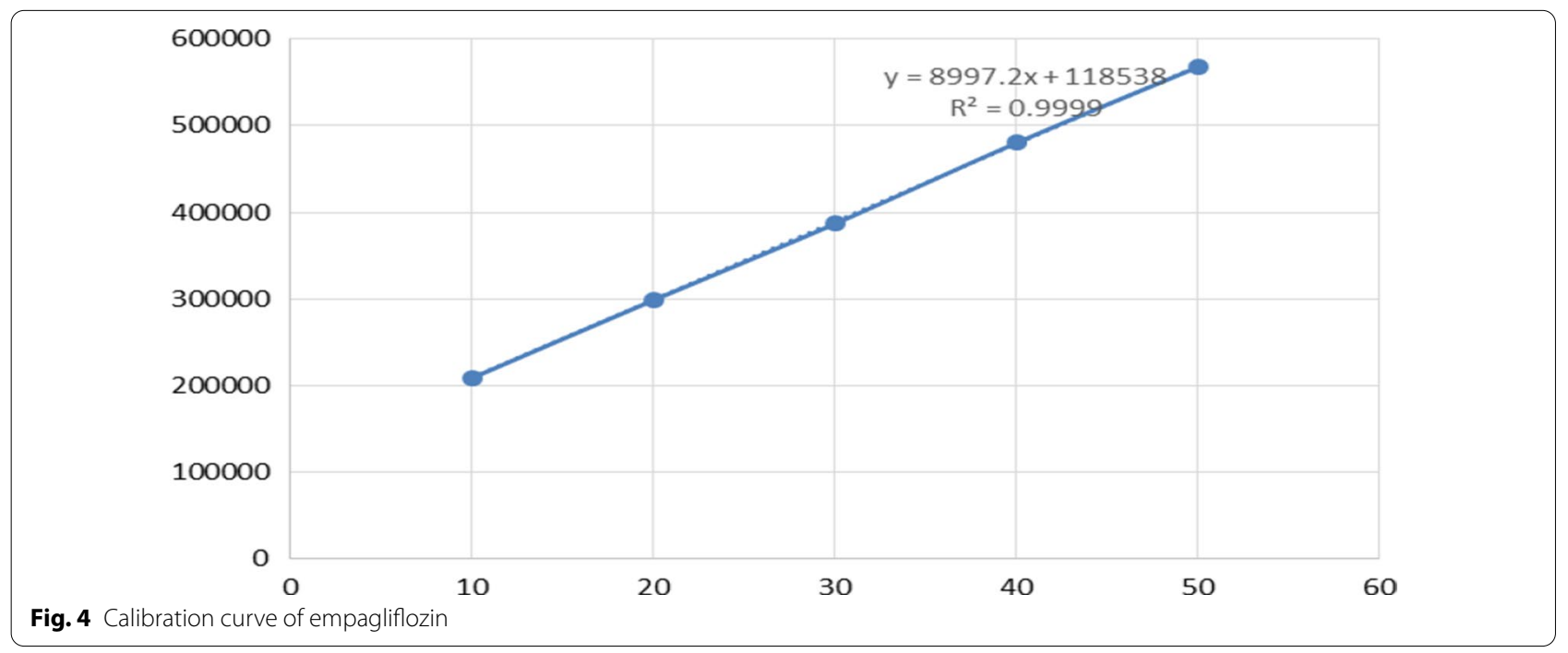


Table 4 Precision data of the RP-HPLC method for empagliflozin

\begin{tabular}{|c|c|c|c|c|c|c|}
\hline \multirow{2}{*}{$\begin{array}{l}\text { Concentration } \\
10 \mu \mathrm{g} / \mathrm{ml}\end{array}$} & \multicolumn{3}{|c|}{ Intra-day study } & \multicolumn{3}{|c|}{ Inter-day study } \\
\hline & Morning & Afternoon & Evening & Day 1 & Day 2 & Day 3 \\
\hline Mean (peak area) & $199,087.6$ & 206,700 & 207,142 & 208,232 & 207,013 & $207,103.3$ \\
\hline SD & 356.36 & 1271.84 & 1976.09 & 1553.71 & 1314.06 & 972.46 \\
\hline$\%$ RSD & 0.17 & 0.61 & 0.95 & 0.74 & 0.63 & 0.46 \\
\hline
\end{tabular}

Table 5 Robustness results at different temperature, flow rate and wavelength for empagliflozin

\begin{tabular}{|c|c|c|c|c|c|c|}
\hline \multirow{2}{*}{$\begin{array}{l}\text { Concentration } \\
10 \mu \mathrm{g} / \mathrm{mL}\end{array}$} & \multicolumn{2}{|c|}{ Rate of flow } & \multicolumn{2}{|c|}{ Temperature } & \multicolumn{2}{|c|}{ Wavelength } \\
\hline & 1.2 & 0.8 & 45 & 25 & 221 & 223 \\
\hline Av. Peak area & $212,002.6$ & 212,171 & $208,647.6$ & $203,863.6$ & $205,108.6$ & $208,213.6$ \\
\hline SD & 928.60 & 1098.15 & 672.21 & 650.37 & 2334.64 & 100.20 \\
\hline$\%$ RSD & 0.4 & 0.5 & 0.3 & 0.3 & 1.1 & 0.04 \\
\hline
\end{tabular}

Table 6 Analysis of marketed formulation

\begin{tabular}{|c|c|c|c|c|}
\hline \multirow[t]{2}{*}{ Marketed formulation } & \multicolumn{3}{|l|}{ Recovered amount } & \multirow{2}{*}{$\begin{array}{l}\text { Claimed } \\
\text { amount } \\
\text { (mg) }\end{array}$} \\
\hline & Amount found (mg) & Recovery $(\%) \pm S D^{*}$ & RSD* (\%) & \\
\hline $\begin{array}{l}\text { Formulation } 1 \text { (Empagliflozin } 25 \text { mg, } \\
\text { excipients qs) }\end{array}$ & 24.97 & $99.90 \pm 0.258$ & 0.258 & 25 \\
\hline $\begin{array}{l}\text { Formulation } 2 \text { (Empagliflozin } 25 \text { mg, } \\
\text { excipients qs) }\end{array}$ & 24.98 & $99.94 \pm 0.240$ & 0.240 & 25 \\
\hline
\end{tabular}

*Average of three determinations of three different concentration

milliliter of samples was taken out at 0-, 4-, 8-, 24-hour time intervals. It was neutralized with same volume of $0.1 \mathrm{~N} \mathrm{NaOH}$ solution and diluted with methanol to get the final concentration of $10 \mu \mathrm{g} / \mathrm{mL}$ of empagliflozin. Sample solutions were then analyzed using the HPLC method. The result obtained from the peak area of the HPLC chromatogram was extrapolated to calculate the actual drug content. In acidic degradation study there was no degradation up to $8 \mathrm{~h}$. It was only after $24 \mathrm{~h}$ that $30 \%$ degradation was seen. Base degradation of empagliflozin was performed in $0.1 \mathrm{~N} \mathrm{NaOH}$ and weighed $10 \mathrm{mg}$ drug accurately and transferred to a $100-\mathrm{mL}$ clean volumetric flask and dissolved in $-10 \mathrm{~mL}$ of methanol as above. The volume was made up with $0.1 \mathrm{~N} \mathrm{NaOH}$ solution and kept at room temperature for observation. One milliliter of samples was taken out at 0-, 4-, 8-, 24-h time intervals, and neutralized with equal value of $0.1 \mathrm{~N} \mathrm{HCl}$ solution. The volume was made up with methanol to get the final concentration of $10 \mu \mathrm{g} / \mathrm{mL}$ of empagliflozin. Samples were then analyzed using the HPLC method. In base stress condition empagliflozin indicated degradation after $8 \mathrm{~h}$ and the percentage of degradation is 30\%. For oxidation $10 \%$ hydrogen peroxide was used. Drug sample $(10 \mathrm{mg})$ was accurately weighed and taken in $5-10 \mathrm{~mL}$ methanol in 100-mL clean volumetric flask and $\mathrm{H}_{2} \mathrm{O}_{2} 10$ $\% \mathrm{v} / \mathrm{v}$ was used to make up the volume. The sample was kept at room temperature for observation. One milliliter of samples was taken out at 0-, 4-, 8-, 24-h time intervals and diluted with methanol to get the final concentration of $10 \mu \mathrm{g} / \mathrm{mL}$ of empagliflozin. Sample solutions were then analyzed using a developed method. In the oxidative degradation study empagliflozin showed 33\% degradation after $8 \mathrm{~h}$.

Empagliflozin was exposed to the direct sunlight and observed for photolytic degradation if any. The drug was kept in a petri dish and kept for 20 days in open light. The samples were collected after 5 and 10 days and these were then analyzed using the HPLC Instrument and followed the procedure discussed in earlier sections. Even after 20 days there was no degradation found. As per the ICH Q1A accelerated testing condition, thermal degradation should be carried out in dry heat or wet heat. Studies may be conducted at high temperatures for a short period. The drug was kept in a petri dish in an oven at $80{ }^{\circ} \mathrm{C}$ for 2 days. Then, the drug content was determined using the procedure as discussed in earlier section after 24 and 48 $\mathrm{h}$. Before handling the drug, the sample was allowed to cool down in a desiccator. In the thermal degradation 
study no degradation was observed even after $48 \mathrm{~h}$. The degradation results are shown in Table 7 and Fig. 5.

\section{Discussion}

Various research articles of the same drug in combination of same category drugs are reported [20-22]. The developed procedure using reverse phase HPLC analysis

Table 7 Results of forced degradation study for empagliflozin

\begin{tabular}{lll}
\hline Stress condition & \% Degradation & $\begin{array}{l}\text { \% Active } \\
\text { drug after } \\
\text { degradation }\end{array}$ \\
\hline Acid degradation & 30 & 70 \\
Basic degradation & 30 & 70 \\
Oxidative degradation & 33 & 67 \\
Photolytic degradation & No degradation & 100 \\
Thermal degradation & No degradation & 100 \\
\hline
\end{tabular}

method for empagliflozin has been developed consisting of separation of the drug on a $\mathrm{C}_{18}$ column equipped with DAD indicator. The best selected solvent system was found to be methanol/acetonitrile/1\%OPA (75:20:05). The flow rate of the solvent system was kept at $1.0 \mathrm{~mL} /$ $\mathrm{min}$. The period required for the separation was obtained at $2.54 \mathrm{~min}$. Linearity was obtained in over the concentration range of $10-50 \mu \mathrm{g} / \mathrm{mL}\left(R^{2}=0.9990\right)$ with a LOD and LOQ of $0.05 \mu \mathrm{g} / \mathrm{mL}$ and $0.1 \mu \mathrm{g} / \mathrm{mL}$, respectively.

The developed procedure was applied to two marketed formulations of these two compositions of empagliflozin $25 \mathrm{mg}$ and excipients to q.s. The analysis obtained was in uniformity in the claimed amount in the marketed sample. Validation performed according to the $\mathrm{ICH}$ guidelines where the results are fast, accurate, robust, specific and linear $[18,19]$.

The separation done on the method was linear over the concentration range of inter-day and intra-day precision and accuracy was between 99.14 and $99.29 \%$. The
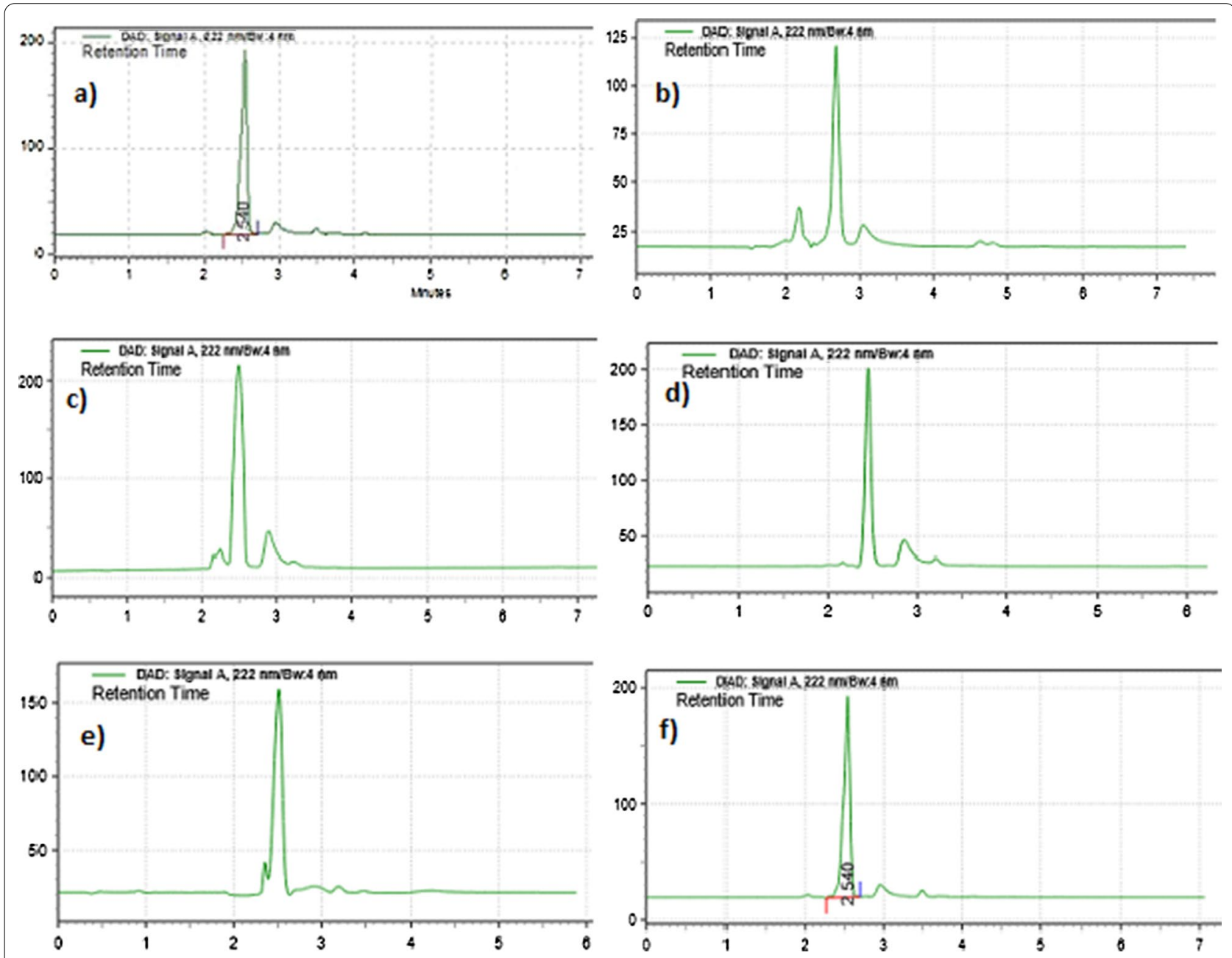

Fig. $\mathbf{5}$ Degradation study in condition of $\mathbf{a}$ control, $\mathbf{b}$ acid, $\mathbf{c}$ base, $\mathbf{d}$ oxidation, $\mathbf{e}$ light, $\mathbf{f}$ heat 
stability-indicating assay was done in the same manner as many reported methods $[23,24]$. In the degradation studies, the drug was stable up to $8 \mathrm{~h}$ in acidic medium, $24 \mathrm{~h}$ in basic medium, and $24 \mathrm{~h}$ under oxidative stress and there was no degradation in heat and light exposure.

\section{Conclusion}

Simple, sensitive and selective stability-indicating HPLC method for estimation of empagliflozin has been developed in pharmaceutical dosage form. On the basis of result and analysis, it is concluded that the method is applicable for the estimation of drug in the formulary of marketed tablet without obstruction from the excipients in the formulation.

The proposed method is true, simple, cost-effective and applicable for routine analysis of drug quality control in laboratories and the pharmaceutical industries. Stability studies have been carried out to assess the stability of the compound and to demonstrate the stability of the RPHPLC method developed.

\section{Abbreviations \\ RP-HPLC: Reverse-phase high-performance liquid chromatography; ICH: International Conference on Harmonization; DAD: Diode array detector; SD: Standard deviation; RSD: Relative standard deviation; LOD: Limit of detection; LOQ: Limit of quantitation; RT: Retention time; C: Intercept; $m$ : Slope; $R^{2}$ : Coef- ficient of determination.}

\section{Acknowledgements}

I am very thankful to GLA University and my Supervisor Dr. Pradeep Mishra for guiding me throughout the work.

\section{Authors' contributions}

Experimental work was done by SP. Both authors equally contributed in framing and writing of manuscript. All authors have read and approved the manuscript.

\section{Funding}

Not applicable.

\section{Availability of data and materials}

Data and material are available upon request.

\section{Declarations}

Ethics approval and consent to participate Not applicable.

\section{Consent for publication}

Not applicable.

\section{Competing interests}

The authors declare that they have no competing interest.

Received: 3 April 2021 Accepted: 22 August 2021

Published online: 30 August 2021

\section{References}

1. Grempler R, Thomas L, Eckhardt M, Himmelsbach F, Sauer A, Sharp DE, Bakker RA, Mark M, Klein T, Eickelmann P (2012) Empagliflozin, a novel selective sodium glucose cotransporter-2 (SGLT-2) inhibitor: characterisation and comparison with other SGLT-2 inhibitors. Diabetes Obes Metab 14(1):83-90

2. Scheen AJ (2015) Pharmacodynamics, efficacy and safety of sodium-glucose co-transporter type 2 (SGLT2) inhibitors for the treatment of type 2 diabetes mellitus. Drugs 75(1):33-59

3. Gerich J (2010) Role of the kidney in normal glucose homeostasis and in the hyperglycemia of diabetes mellitus: therapeutic implications. Diabet Med 27(2):136-142

4. Hedrington MS, Davis SN (2015) The role of Empagliflozin in the management of type 2 diabetes by patient profile. Ther Clin Risk Manag 11:739-749

5. Syed SH, Gosavi S, Shami W, Bustamante M, Farah Z, Teleb M, Abbas A, Said S, Mukherjee D (2015) A review of sodium glucose co-transporter 2 inhibitors canagliflozin, dapagliflozin and empagliflozin. Cardiovasc Hematol Agents Med Chem 13(2):105-112

6. Padmaja N, Veerabhadram G (2016) Method development and validation of RP-HPLC method for the estimation of empagliflozin in API. Int J pharm Sci Res 7(2):724-727

7. Shymala SM, Sangeetha E, Mahender L (2016) Method development and validation of Empagliflozin by RP-HPLC in bulk and pharmaceutical dosage form. Pharmanest 7(1):3040-3042

8. Kavuluru VSK, Kothapalli BCS (2018) Development, characterization and evaluation of Empagliflozin spherical agglomerates using spherical agglomeration technique. J Pharm Innov 7(3):202-207

9. Jaiswal SH, Katariya MV, Katariya VR, Karva GS, Koshe K (2017) Validated stability indicating HPLC method for determination of process related impurities in empagliflozin drug substances. World J Pharm Res 6(7):1025-1037

10. Ayoub BM, Mowaka S, Elzanfaly ES, Ashoush N, Elmazar MM, Mousa SA (2017) Pharmacokinetic evaluation of empagliflozin in healthy egyptian volunteers using LC-MS/MS and comparison with other ethnic populations. Sci Rep 7(1):2583

11. Padmaja N, Babu MS, Veerabhadram G (2016) Stability-indicating RP-HPLC analytical method development and validation for the Metformin and Empagliflozin in pharmaceutical dosage form. Jdeafrikana 3(5):314-328

12. Godasu S, Sreenivas S (2017) A new validated RP-HPLC method for the determination of Metformin HCL and Empagliflozin in its bulk and pharmaceutical dosage forms. Int J Pharm Sci Res 8(5):2223-2232

13. Pratyusha CR, Raju MB (2016) Development and validation of stability indicating RP-HPLC method for the simultaneous estimation of Metformin hydrochloride and Empagliflozin in bulk and in a synthetic mixture. Int J Pharm 6(4):138-147

14. Madana GN, Sridhar C (2017) Validated stability indicating ultra-performance liquid chromatographic method for simultaneous determination of Metformin and Empagliflozin in bulk drug and tablet dosage form. Int J Appl Pharm 9(3):45-50

15. Naazneen S, Sridevi A (2016) Development and validation of stability indicating RP-HPLC method for simultaneous estimation of empagliflozin and linagliptin in tablet formulation. Der Pharm Lett 8(17):57-65

16. Devanna N (2015) RP-HPLC method development and validation for simultaneous determination of linagliptin and empagliflozin in tablet dosage form. Int Adv Res 2(2):95-99

17. Bhole R, Wankhede S, Pandey M (2017) Stability indicating HPTLC method for simultaneous estimation of empagliflozin and linagliptin in pharmaceutical formulation. Anal Chem Lett 7(1):76-85

18. ICH (2005) ICH topic Q2(R1) validation of analytical procedure: text and methodology

19. Yasmin M, Christine K, Adel M, Hayam M (2017) Validated stability-indicating chromatographic methods for the determination of chlordiazepoxide and clidinium bromide in the presence of its alkali-induced degradation product: kinetic study. Chromatographia 80(6):911-922

20. Khalil GA, Salama I, Gomaa MS, Helal MA (2018) Validated RP-HPLC method for simultaneous determination of Canagliflozin, Dapagliflozin, Empagliflozin and Metformin. Int J Pharm Chem Biol Sci 8(1):1-13

21. Hassib ST, Taha EA, Elkady EF, Barakat GH (2019) Validated liquid chromatographic method for the determination of (canagliflozin, dapagliflozin or empagliflozin) and metformin in the presence of (1-cyanoguanidine). J Chromatogr Sci 57(8):697-707

22. Ayoub BM (2015) UPLC simultaneous determination of empagliflozin, linagliptin and metformin. RSC Adv 5:95703-95709 
23. Adel M, Mamdouh R, Hayam M, Mostafa A (2015) Comparative study of multi-variate and uni-variate determination of zolmitriptan in the presence of its degradation products. Anal Chem Lett 5(2):73-84

24. Bagal D, Nagar A, Joshi A (2021) Development and validation of stabilityindicating RP-HPLC method for estimation of Dalfampridine in bulk drug and tablet dosage form. Future J Pharm Sci 7:87

\section{Publisher's Note}

Springer Nature remains neutral with regard to jurisdictional claims in published maps and institutional affiliations.

\section{Submit your manuscript to a SpringerOpen ${ }^{\circ}$ journal and benefit from:}

- Convenient online submission

- Rigorous peer review

- Open access: articles freely available online

- High visibility within the field

- Retaining the copyright to your article

Submit your next manuscript at $\boldsymbol{\nabla}$ springeropen.com 